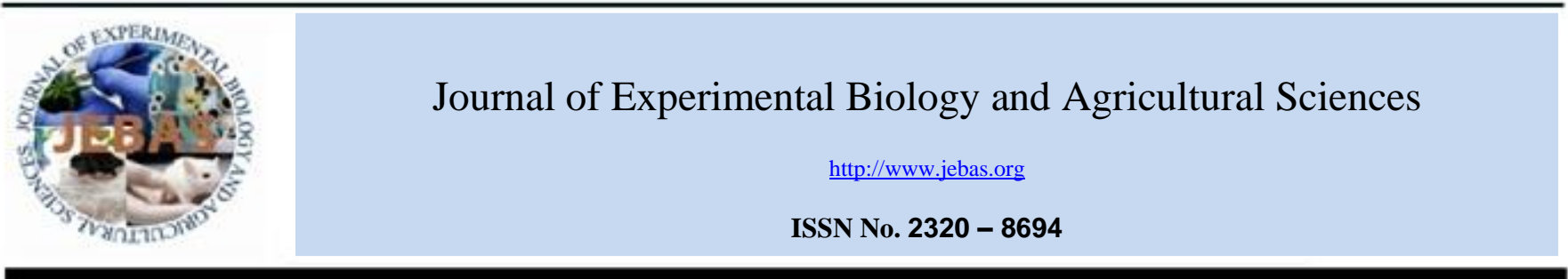

\title{
DISSOLUTION IMPROVEMENT OF KETOPROFEN THROUGH POLYMER MATRIX COMPOSITE POVIDONE K-30/TiO ${ }_{2}$
}

\author{
Aliyah*, Eka Tri Saputri, Diana Fitriah, Andi Arjuna
}

Pharmaceutics, Faculty of Pharmacy, Hasanuddin University, Jl. Perintis Kemerdekaan No.10, Makassar, Sulawesi Selatan, 90245 , Indonesia

Received - December 19, 2020; Revision - March 29, 2021; Accepted - May 04, 2021

Available Online - September 08, 2021

DOI: http://dx.doi.org/10.18006/2021.9(Spl-2-ICOPMES_2020).S234.S240

\section{KEYWORDS \\ Dissolution profile \\ Ketoprofen \\ Polymer matrix composite \\ Povidone K30 \\ $\mathrm{TiO}_{2}$}

\begin{abstract}
Ketoprofen is a nonsteroidal anti-inflammatory drug that has been classified into Class II as per the Biopharmaceutics Classification System. This substance has low solubility i.e. only $51 \mathrm{mg} / \mathrm{L}$ at $22^{\circ} \mathrm{C}$. Therefore, a study of ketoprofen modification prepared in Polymer Matrix Composite (PMC) using Povidone K-30, coated with $\mathrm{TiO} 2$ as an effort to improve its dissolution profile, had been conducted. Composite particles were prepared through a dissolving method with a ratio of ketoprofen: Povidone K30 i.e. 1: 1 (F1), 1: $2(\mathrm{~F} 2)$, and 1: $4(\mathrm{~F} 3)$. They were evaluated and continued on the coating process using $\mathrm{TiO} 230 \%, 40 \%$, and 50\%. Results of the study revealed that the PMC provides an absence of chemical intervention against ketoprofen. All the used combination ratios improved the dissolution profile by using phosphate buffer media $\mathrm{pH} 7.5$ for 60 minutes. After coating, a release profile was obtained by running it on phosphate buffer media at $\mathrm{pH} 6.8$ for 8 hours, this showing a sustained release profile.
\end{abstract}

* Corresponding author

E-mail: aliyah@unhas.ac.id (Aliyah)

Peer review under responsibility of Journal of Experimental Biology and Agricultural Sciences.

Production and Hosting by Horizon Publisher India [HPI] (http://www.horizonpublisherindia.in/).

All rights reserved.
All the articles published by Journal of Experimental Biology and Agricultural Sciences are licensed under a Creative Commons Attribution-NonCommercial 4.0 International License Based on a work at www.jebas.org.

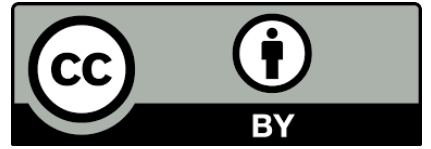




\section{Introduction}

Ketoprofen is a propionic acid derivative, non-steroidal antiinflammatory drug (NSAID), which is used as an analgesic, antipyretic and anti-inflammatory. This active pharmaceutical ingredient of the drug has been categorized as Class II, in the Biopharmaceutics Classification System (BCS), which has low solubility $\left(51 \mathrm{mg} / \mathrm{L}\right.$ at $\left.22^{\circ} \mathrm{C}\right)$, and high permeability (Grimling et al., 2014; Himawan et al., 2019). It has been claimed that this character may affect the low dissolution rate of ketoprofen, leading to imperfect absorption and poor bioavailability (Rençber et al., 2009; Grimling et al., 2014). In addition, ketoprofen also has gastrointestinal side effects which causing gastric irritation, especially during repeated administration. To overcome this, researchers have been studying to find a simple system that could increase the solubility of the drug (Saffoon et al., 2011), and possibly reduce the side effects of NSAID like ketoprofen. Drug release modification of ketoprofen into a sustained-release system is achievable, which can lead to reducing its dose as once-daily (Schumacher Jr, 1994; Ibrahim et al., 2010). As in this study, the development of formulas containing NSAIDs using ketoprofen as a model can be achieved through the simple method, a composite particle system.

Composite particles using a polymer as known Polymer Matrix Composite (PMC) is one simple technique completed with a coating process to control drug release (Wang et al., 2011; Dang et al., 2012; Kamari \& Ghiaci, 2016). The PMC combines two or more components that have different characteristics and convert them into a new material with specific characteristics. The solubility of active pharmaceutical ingredients (API) that are difficult to dissolve could be increased through this system, which directly affecting the API's dissolution rate. In general, the composite particle may appear as three types, namely ceramic matrix composite (CMC), metal matrix composite (MMC) and polymer matrix composite (PMC) (Teti, 2002; Wang et al., 2011).

PMC is the most commonly used modification because it is a simple, reliable, and less expensive technique. PMC is formed from reinforcing material and its matrix. The matrix consists of polymeric materials, which will cause the other components to be dispersed in the polymer used. Various studies have been applying to polymer matrices to improve dissolution rates and drug release (Teti, 2002; Bazzo et al, 2009; Wang et al., 2011). Povidone or polyvinyl pyrrolidone is an inert polymer made from the monomer $\mathrm{N}$-vinylpyrrolidone. This polymer has the characteristics of being soluble in water and other organic solvents and provides the ability to increase drug dissolution and release by forming pores (Kazarian \& Martirosyan, 2002; Franco \& De Marco, 2020).

Povidone has been categorized as safe by the FDA and is widely used as a drug carrier to increase drug solubility and control drug crystallization (Frizon et al., 2013). Thus, in this study povidone has been used to improve the solubility of ketoprofen in the composite matrix. In addition, the use of a biocompatible coating of $\mathrm{TiO}_{2}$ played an important role in particle surface modification. Titanium dioxide could offer proper dispersion of the polymer matrix and provide optimum product yields. Furthermore, it formed a physical bridge API to the polymer matrix preventing drug degradation (Sabzi et al., 2009). Therefore, using $\mathrm{TiO}_{2}$ as a coating matrix for composite particle ketoprofen had been also studied. Thus, proper dispersion of the polymer matrix is achievable, leading to the formation of physical interactions with the polymer matrix (Sabzi et al., 2009). The proportion of active pharmaceutical ingredients to the polymer-like povidone $\mathrm{K}-30$, combined with $\mathrm{TiO} 2$ coatings is a vital step for composite particle formulation. Therefore, in this study povidone K-30 as a polymer matrix was used to improve the dissolution profile of ketoprofen. The opportunity of controlling the ketoprofen release had also been evaluated by using $\mathrm{TiO}_{2}$ as a coating to form a ketoprofen composite.

\section{Materials and Methods}

Ketoprofen (Pharmaceutical grade), povidone K-30 (Dwilab mandiri), N-hexane, phosphate buffer $\mathrm{pH} 6.8$, phosphate buffer $\mathrm{pH}$ 7.5 , ethanol $96 \%, \mathrm{HCl}$ pro-analysis, sodium dihydrogen phosphate, disodium hydrogen phosphate, and titanium dioxide, were provided by Pharmaceutic laboratory, Faculty of Pharmacy, Hasanuddin University.

\subsection{Preparation of composite particle ketoprofen - povidone K-} 30 (CPKP)

The composite was prepared by dissolving method, with the proportion of ketoprofen : povidone $\mathrm{K}-30$ in formula CPKP F1 (1:1), F2 (1:2), and F3 (1:4). Each proportion of ketoprofen and povidone K-30 were put in a and completely dissolved with $96 \%$ ethanol. The solution was then poured into a petri dish and dried in a granule dryer at a temperature of $\pm 40^{\circ} \mathrm{C}$ until a composite particle was obtained. The solid formed was also sieved with a sieve number 20 (Bazzo et al., 2009; Frizon et al., 2013).

\subsection{The intervention test between ketoprofen as active pharmaceutical ingredients and adjuvants}

Ketoprofen and composite product were dissolved in phosphate buffer $\mathrm{pH} 7.5$ with a concentration of $10 \mathrm{ppm}$. The absorption was then measured in the 200 - $400 \mathrm{~nm}$ wavelength range using a UVVis spectrophotometer. The presence or absence of a shift in the maximum absorption wavelength in the composite particle was observed.

\subsection{The dissolution test of the composite particle ketoprofen : povidone K-30 (CPKP) products}

The dissolution test product was carried out using the paddle method (USP-NF, 2018). A composite particle which is equivalent 
to $100 \mathrm{mg}$ of ketoprofen was inserted into the capsule shell. Then, $900 \mathrm{ml}$ of $\mathrm{pH} 7.5$ phosphate buffer as dissolution media place at $37 \pm 0.5^{\circ} \mathrm{C}$ in a chamber and stirred at a speed of $50 \mathrm{rpm}$. The solution in the flask was sustainably sampled using $5 \mathrm{ml}$ Millipore at the period of $5,10,15,30,45$ and 60 minutes. The taken solution as a sample was measured for its absorption at the $\lambda_{\max }$ of ketoprofen using a UV spectrophotometer.

\subsection{The coating of CPKP product with $\mathrm{TiO}_{2}$}

The CPKP product which had the optimum dissolution profile was taken equivalently to $100 \mathrm{mg}$ of ketoprofen and dispersed into 20 $\mathrm{ml}$ of n-hexane, stirred at a speed of $800 \mathrm{rpm}$, at room temperature. $\mathrm{TiO}_{2}$ at $30 \%, 40 \%$ and $50 \%$ was respectively mixed into $5 \mathrm{ml}$ of $\mathrm{n}-$ hexane and added dropwise into the stirred phase of CPKP. Furthermore, the mixture was left for 24 hours, this was followed by the filtration and drying to form composite particles having ketoprofen : povidone $\mathrm{K}-30 / \mathrm{TiO}_{2}$ coating (Sabzi et al., 2009).

2.5 The determination of dissolved ketoprofen in the coated products

Each composite particle ketoprofen : povidone $\mathrm{K}-30 / \mathrm{TiO}_{2}$ was weighed as $10 \mathrm{mg}$, and dissolved in each $0.1 \mathrm{~N} \mathrm{HCL}$, and phosphate buffer pH 6.8 to $10 \mathrm{ml}$. The solution was piped $0.1 \mathrm{ml}$, and the volume was sufficient to $5 \mathrm{ml}$. Dissolved ketoprofen was determined by measuring the absorption using a UV-Vis spectrophotometer at the $\lambda_{\max }$ of ketoprofen with previously having a standard curve.

2.6 The dissolution test of the coated products in phosphate buffer pH 6.8

The dissolution test of the coated products was carried out as described in section 2.3. However, for this product, the test had been conducted using two dissolution media, namely $0.1 \mathrm{~N} \mathrm{HCl}$, and phosphate buffer $\mathrm{pH} 6.8$. The sample solution was taken at 15 , $30,45,60,90$ and 120 minutes intervals for the acid media, and at 1, 2, 3, 4, 6 and 8 hours for the phosphate buffer media.

\subsection{The kinetics model of ketoprofen released from coated composite particles}

The drug release kinetics was determined according to zero-order, first-order, and Higuchi kinetics (Mircioiu et al., 2019). The zeroorder kinetics model is obtained by plotting the cumulative drug dissolved (\%) against time. The first-order kinetics model is obtained by plotting the curve between the logarithms of a cumulative drug (\%) remaining against time, and the Higuchi kinetics model is obtained by plotting the curve of a cumulative drug (\%) dissolved against the root of time. The best-suit drug release kinetics was determined through the correlation coefficient (r) value obtained in each kinetics model. The highest correlation coefficient (closest to 1) can be assumed to be a model of formula release kinetics (Holowka \& Bhatia, 2014; Mohammadian et al., 2018).

\section{Results and Discussion}

Composite particle ketoprofen : povidone K-30 (CPKP) is formulated through Polymer Matrix Composite (PMC) using povidone $\mathrm{K}-30$ as polymer, resulting products were hygroscopic, and having small crystals-like shards form (Figure 1).

Following the process, the observation of chemical intervention among the compositions was subsequently performed. The possibility of chemical interactions occurred between ketoprofen as the active pharmaceutical ingredient, and adjuvants were evaluated using a UV-Vis spectrophotometer at the $\lambda=200-400$ $\mathrm{nm}$, by observing at the maximum wavelength of each product compared to unmodified ketoprofen. As depicted in Figure 2, each product CPKP, compared to ketoprofen have the similarity for the maximum wavelength $(259.8-260.6 \mathrm{~nm})$, in a slight change in respective absorbance values. This trend implies the absence of chemical interaction, and the existence of physical interaction between ketoprofen to the polymer, which is also confirming the dynamic organoleptic appearance previously described in Figure 1.

In terms of dissolution profile, the evaluation was conducted as described in the monograph, Indonesian Pharmacopoeia ed. V and <711> Dissolution, USP. The dissolved ketoprofen was determined using a UV-Vis spectrophotometer at the ketoprofen $\lambda_{\text {maks, }}$, through paddle method in phosphate buffer ( $\mathrm{pH}$ 7.5) for 60 minutes.

As presented in Figure 3, there is an increasing trend in the dissolution rate of each product (F1 to F3) compared to ketoprofen. The dissolved ketoprofen at F1, F2 and F3 at 45 minutes were $46.95 \pm 0.23 \%, 56.89 \pm 0.16 \%$ and $82.31 \pm 0.38 \%$, respectively. This shows that F3 fulfils the monograph requirements for ketoprofen dissolution set by the Indonesian Pharmacopoeia, which should be greater than $70 \%$. In the case of F1, and F2, the dissolution rate was also higher than standard but having unmet requirements. The greater concentration of povidone-K30 in the F3 clearly describes the important effect of the hydrophilic polymer in improving the dissolution rate of hydrophobic NSAID like ketoprofen.

Furthermore, to study the opportunity in improving the drug release of the CPKP, F3 as the optimum formula met the standard requirement, was then charted to the coating process. The F3 was subsequently processed to the coating step with three variant proportions (30\% (FT1), 40\% (FT2), and 50\% (FT3)) of $\mathrm{TiO} 2$ as coating material. The dissolution profile of those coated composite particles was determined in both acid and base media through the paddle method, both in $\mathrm{HCl} 0.1 \mathrm{~N}, 120$ minutes (Figure 4), and in phosphate buffer $\mathrm{pH} 6.8$ for 8 hours (Figure 5). 

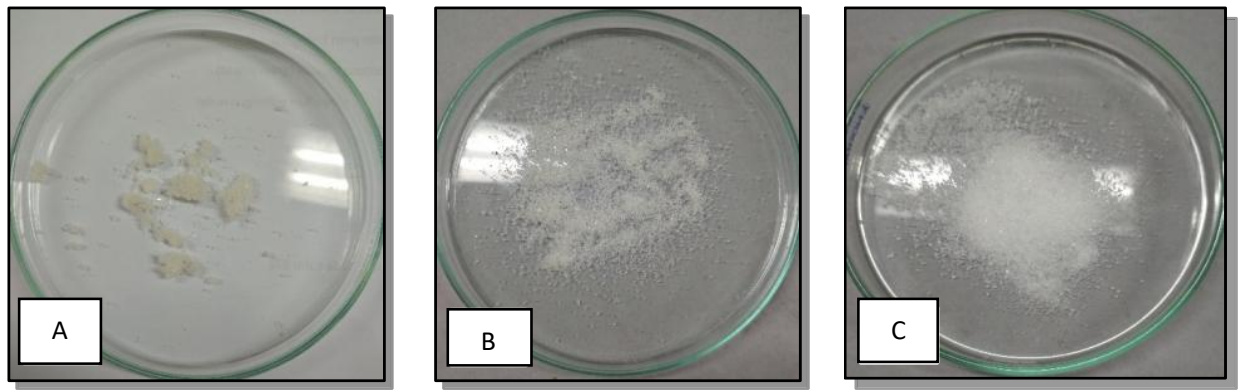

Figure 1 The organoleptic appearances of composite particle A. F1 ketoprofen : povidone K-30 (1:1);

B. F2 ketoprofen : povidone K-30 (1:2); C. F3 ketoprofen : povidone K-30 (1:4)

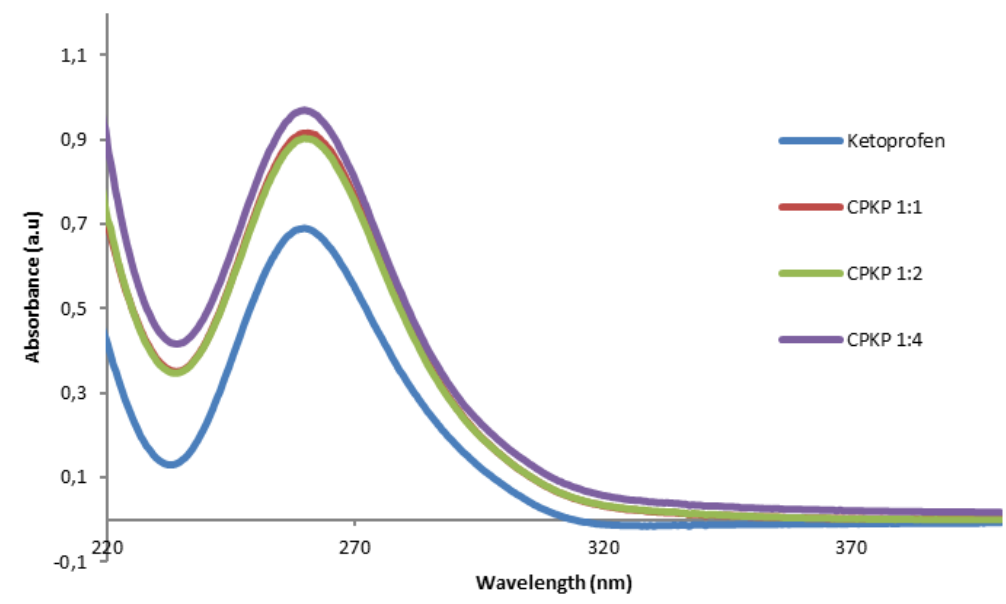

Figure 2 The UV-Vis spectra of ketoprofen compared to each product CPKP F1 ketoprofen : povidone K-30 (1:1), CPKP F2 ketoprofen : povidone K-30 (1:2), and CPKP F3 ketoprofen : povidone K-30 (1:4)

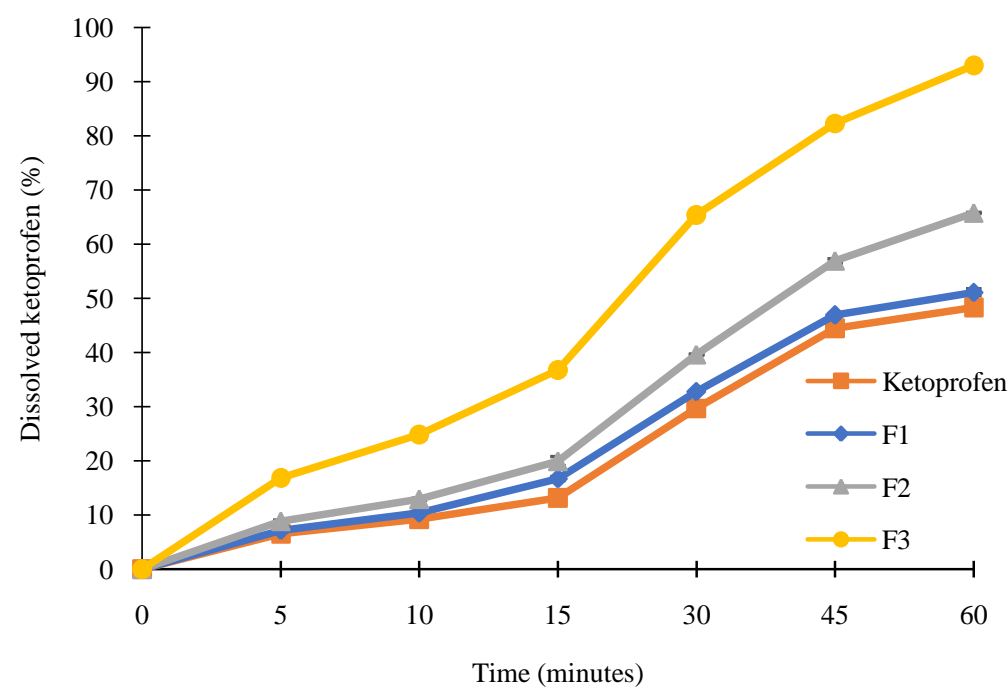

Figure 3. The dissolution profile of ketoprofen compared to each products F1 ketoprofen : povidone K-30 (1:1), F2 ketoprofen : povidone K-30 (1:2), and F3 ketoprofen : povidone K-30 (1:4).

Journal of Experimental Biology and Agricultural Sciences http://www.jebas.org 


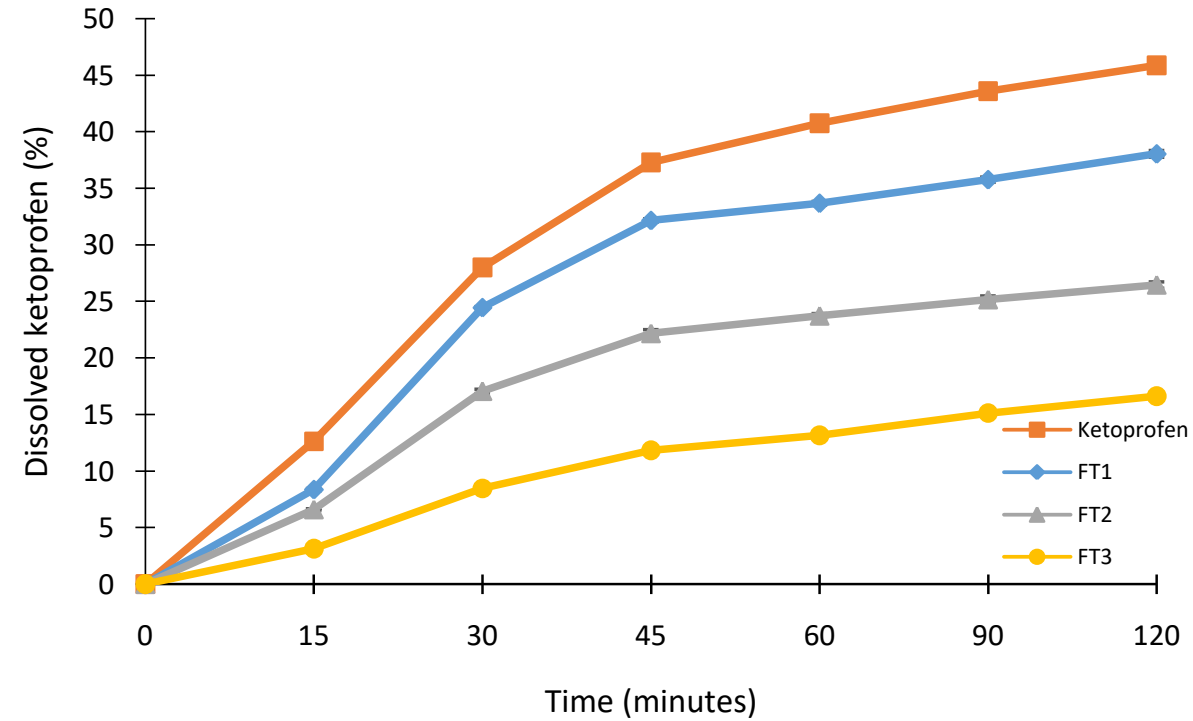

Figure 4 The dissolution profile of ketoprofen compared to each products FT1 ketoprofen : povidone K-30 (1:4)/ $30 \% \mathrm{TiO}_{2}$, FT2 ketoprofen : povidone $\mathrm{K}-30(1: 4) / 40 \% \mathrm{TiO}_{2}$, and FT3 ketoprofen : povidone $\mathrm{K}-30(1: 4) / 50 \% \mathrm{TiO}_{2}$ in $0.1 \mathrm{~N} \mathrm{HCl}$ media.

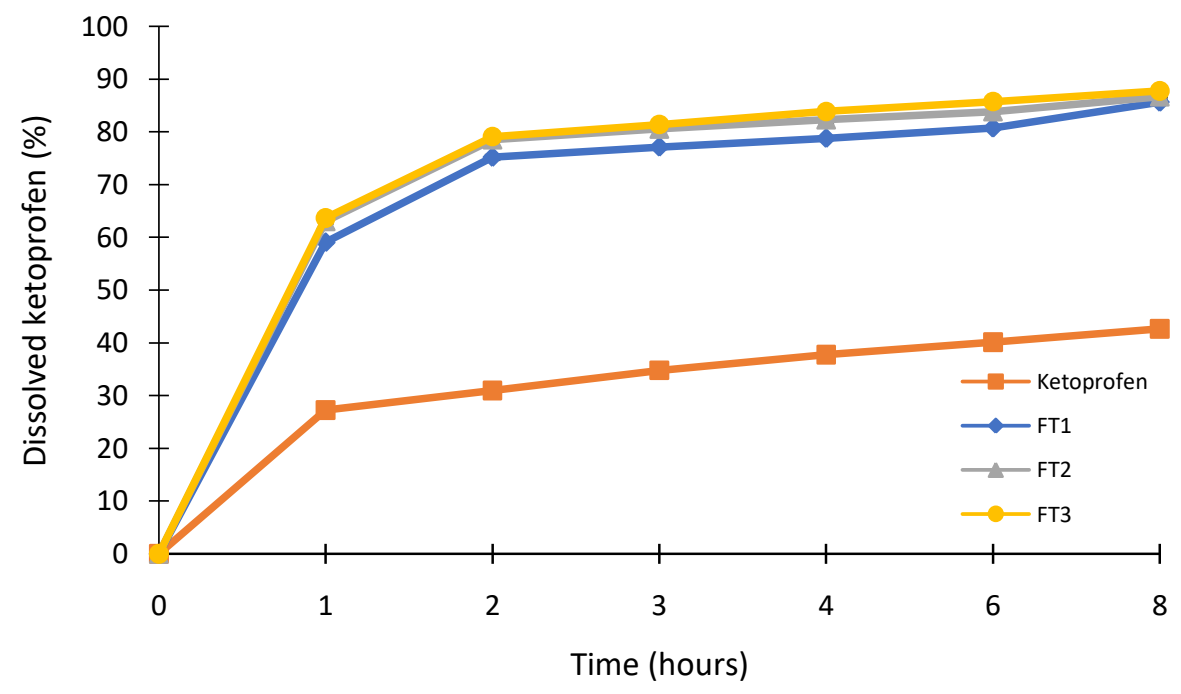

Figure 5 The dissolution profile of ketoprofen compared to each products FT1 ketoprofen : povidone $\mathrm{K}-30(1: 4) / 30 \% \mathrm{TiO}_{2}$, FT2 ketoprofen : povidone K-30 (1:4)/ $40 \% \mathrm{TiO}_{2}$, and FT3 ketoprofen : povidone $\mathrm{K}-30(1: 4) / 50 \% \mathrm{TiO}_{2}$ in phosphate buffer media.

Table 1 The kinetics correlation coefficient of coated composite particle F3

\begin{tabular}{|c|c|c|c|}
\hline \multirow{2}{*}{ Formula } & \multicolumn{3}{|c|}{ Correlation coefficient (r) } \\
\hline & Zero-order & First-order & Higuchi \\
\hline FT3 & 0.8122 & 0.9101 & 0.8810 \\
\hline
\end{tabular}

As presented in figure 4, the coated composite products (FT1 to FT3) in $0.1 \mathrm{~N} \mathrm{HCl}$ media having a decreasing pattern in dissolution rate compared to ketoprofen. As expected, $\mathrm{TiO} 2$ in this formulation would reduce the rate of drug release. In the first 15 minutes, all formulas have provided slightly ketoprofen been released. It less than $10 \%$ dissolve ketoprofen, increase in gradual pattern until 120 minutes, where FT1 released the highest ketoprofen $(38.06 \%)$ compared to other products, which was controllable below the concentration of unmodified ketoprofen (45.88\%). The great slower dissolution rate in FT3 might be due to

Journal of Experimental Biology and Agricultural Sciences http://www.jebas.org 
the use of $50 \% \mathrm{TiO} 2$ that may have strong hydrogen bonds between titanium dioxide to povidone K-30 (Kamari \& Ghiaci, 2016).

In contrast to the dissolution profile depicted in figure 5, each product in buffer phosphate has an increasing trend compared to unmodified ketoprofen. In the first hour, all formulas have released ketoprofen more than $50 \%$, followed by a gradual decrease. As stated in the monograph, within 8 hours, ketoprofen has to be released more than $80 \%$. Thus, all formulas suit this requirement, where FT1 released $85.66 \%$ ketoprofen, FT2; 86,69\%, and FT3 released the highest concentration at $87.77 \%$ compared to unmodified ketoprofen which only stood at $42.7 \%$. The results analysis of the variety of ketoprofen dissolved in phosphate buffer media pH 6.8 for 8 hours in three formulas (FT1, FT2, FT3) found to be a very significant difference (Significant level <1\%). Furthermore, using the Tukey test, the highest dissolved ketoprofen results were obtained at FT3 $(87.77 \%)$, which was followed by FT2 $(86.69 \%)$ and FT1 $(85.66 \%)$, respectively.

Considering FT3 has provided the lowest release in acid media, and the highest release in alkali media, a kinetic study of ketoprofen in this formula is further studied. The drug, ketoprofen release data were then plotted based on the zero-order, first-order and Higuchi equations (Shohin et al., 2012; Mircioiu et al., 2019).

The determination of ketoprofen released from coated composite particles was carried out by comparing the correlation coefficient of each drug release kinetic model (zero-order, first-order, and Higuchi). As presented in table 1, the correlation coefficient value that was closest to 1 , (0.9101) was determined to be the best kinetics model describing the ketoprofen release out of the matrix in phosphate buffer media. This implied that FT3 product has released ketoprofen according to the first-order kinetics, in which the product has sustained release kinetics.

\section{Conclusion}

Composite particle ketoprofen : povidone K-30, especially in the proportion $1: 4$, had improved the dissolution profile $(92.74 \%)$ of ketoprofen without involving chemical intervention. Furthermore, $\mathrm{TiO}_{2}$ provide a positive impact on ketoprofen released in the polymer matrix composite to be a sustained-release follows the first-order kinetics.

\section{Acknowledgement}

The authors are highly thankful to the Lab. Pharmaceutics, Faculty of Pharmacy Hasanuddin University.

\section{Conflict of interest}

All the authors declare that there is no conflict of interest.

\section{References}

Bazzo GC, Lemos-Senna E, Pires ATN (2009) Poly (3hydroxybutyrate)/chitosan/ketoprofen or piroxicam composite microparticles: preparation and controlled drug release evaluation. Carbohydrate Polymers 77(4): 839-844.

Dang ZM, Yuan JK, Zha JW, Sheng TZ, HualHu TG (2012) Fundamentals, processes and applications of high-permittivity polymer-matrix composites. Progress in materials science 57(4): $660-723$.

Franco P, De Marco I (2020) The Use of Poly (N-vinyl pyrrolidone) in the Delivery of Drugs: A Review. Polymers 12(5): 1114.

Frizon F, de Oliveira Eloya J, Donaduzzib CM, Mitsuib ML, Marchettia JM (2013) Dissolution rate enhancement of loratadine in polyvinylpyrrolidone $\mathrm{K}-30$ solid dispersions by solvent methods. Powder Technology 235: 532-539.

Grimling B, Górniak A, Meler J, Szcześniak M (2014) Characterisation and dissolution properties of ketoprofen In binary solid dispersion with chitosan. Progress on Chemistry and Application of Chitin and its Derivatives 19: 23-31.

Himawan A, Djide NJN, Mudjahid M, Lukita ADI, Arjuna A, Aliyah (2019) 'Physicochemical and Micromeritics Properties of Ketoprofen-Tartaric Acid Binary System. Journal of Physics: Conference Series IOP Publishing, 1341(7): 72004.

Holowka EP, Bhatia SK (2014) Controlled-release systems. Drug delivery. Springer, New York, NY. https://doi.org/10.1007/978-14939-1998-7_2.

Ibrahim MA, Amin MA, Fetih G, Abou Ela A (2010) Formulation and evaluation of ketorolac tromethamine-Eudragit solid dispersions of potential sustained-release properties. STP Pharma Pratiques 20(3): 189.

Kamari Y, Ghiaci M (2016) Preparation and characterization of ibuprofen/modified chitosan/TiO2 hybrid composite as a controlled drug-delivery system. Microporous and Mesoporous Materials 234: 361-369.

Kazarian SG, Martirosyan GG (2002) Spectroscopy of polymer/drug formulations processed with supercritical fluids: in situ ATR-IR and Raman study of impregnation of ibuprofen into PVP. International Journal of Pharmaceutics 232(1-2): 81-90.

Mircioiu C, Voicu V, Anuta V, Tudose A, Celia C, Paolino D, Fresta M, Sandulovici R, Mircioiu I (2019) Mathematical modeling of release kinetics from supramolecular drug delivery systems. Pharmaceutics 11(3): 140.

Journal of Experimental Biology and Agricultural Sciences http://www.jebas.org 
Mohammadian M, Kashi TSJ, Erfan M, Soorbaghid FP (2018) Invitro study of Ketoprofen release from synthesized silica aerogels (as drug carriers) and evaluation of mathematical kinetic release models. Iranian Journal of Pharmaceutical Research 17(3): 818.

Rençber S, Karavana SY, Özyazici M (2009) Bioavailability file: ketoprofen. FABAD Journal of Pharmaceutical Sciences 34(4): 203.

Sabzi M, Mirabedini SM, Zohuriaan-Mehr J, Atai M (2009) Surface modification of $\mathrm{TiO} 2$ nano-particles with silane coupling agent and investigation of its effect on the properties of polyurethane composite coating. Progress in Organic Coatings 65(2): 222-228.

Saffoon N, Uddin R, Huda NH, Sutradhar KB (2011) Enhancement of oral bioavailability and solid dispersion: a review. Journal of Applied Pharmaceutical Science 1(7):13-20.
Schumacher Jr, HR (1994) Ketoprofen extended-release capsules: a new formulation for the treatment of osteoarthritis and rheumatoid arthritis. Clinical Therapeutics 16(2): 145-159.

Shohin IE, Kulinich JI, Ramenskaya GV, Abrahamsson B, Kopp S, Langguth P, et al. (2012) Biowaiver monographs for immediaterelease solid oral dosage forms: ketoprofen. Journal of Pharmaceutical Sciences 101(10): 3593-3603.

Teti R (2002) Machining of composite materials. CIRP Annals 51(2): 611-634.

USP-NF (2018) The United States Pharmacopeia and the National Formulary. The United States Pharmacopeial Convention.

Wang RM, Zheng SR, Zheng YG (2011) Polymer matrix composites and technology. Elsevier Publication. 